\title{
PENGARUH FIT UP JOINT ERECTION TERHADAP KUALITAS SAMBUNGAN LAS PADA LAMBUNG KAPAL
}

\author{
Sulaiman , Sunarso Sugeng \\ Program Studi D3 Teknologi Perancangan dan Konstruksi Kapal, Departemen Teknologi Industri, \\ Sekolah Vokasi , Universitas Diponegoro Semarang \\ Jl. Prof. Soedarto, SH, Kampus Undip Tembalang, Semarang 50275 \\ Email:
}

\begin{abstract}
Abstrak
Seiring dengan perkembangan teknologi yang semakin pesat di dunia pelayaran, ia telah menciptakan banyak metode terbaru yang ditemukan. Baik dalam sistem pengembangan, dan sebagainya. Metode pengembangan yang digunakan dalam proses pembuatan kapal sangat berpengaruh dalam memperkirakan penyelesaian pekerjaan, biaya yang dikeluarkan, dan hasil kualitas yang baik. Dalam metode pengembangan ini ada beberapa proses yang harus dilewati dalam proses salah satunya adalah proses Penggabungan Blok (Joint Erection) yang dilakukan untuk mengkoneksi dengan blok balok lain menjadi satu bagian kapal yang utuh. Dalam proses Joint Erection proses Fit Up yang dilakukan sangat penting untuk mendapatkan koneksi antar blok yang baik dan benar. Fit Up adalah proses koneksi dua blok menjadi satu salam suatu parameter. Dalam proses pembangunan Kapal Patroli Kelas-A2-55 meter menggunakan metode sistem blok sehingga proses Fit Up diperlukan dalam pengembangan ini untuk memenuhi standar dan kualitas yang diinginkan. Dengan metode pengembangan yang lebih cepat dan mudah itu akan berdampak pada kepuasan setiap pelanggan terutama di dunia pelayaran.
\end{abstract}

Kata Kunci : "Ereksi”, “Fit up”, "Pengelasan”

\section{Pendahuluan}

Dalam proses pembuatan kapal ada beberapa metode atau cara pembuatan kapal terdiri dari dua cara yaitu cara pertama berdasarkan sistem, cara kedua berdasarkan tempat. Dalam pembuatan kapal berdasarkan sistem ada tiga macam yaitu : sistem seksi, sistem konvensional, sistem block. Dengan proses pembuatan kapal menggunakan metode block biasanya untuk membuat kapal-kapal besar, penulis tertarik dengan proses pembuatan kapal dengan metode sistem block [2].

Perkembangan ilmu pengetahuan dan teknologi yang semakin pesat seiring dengan kemajuan zaman. Peningkatan industrilisasi di bidang perkapalan dari masa ke masa mendorong terciptanya pertumbuhan daya saing antara perusahaan. Maka untuk dapat mengatasi dan meningkatan daya saing tersebut diperlukan pengelolaaan yang bak terhadap semua komponen dalam perusahaan yang berkualitas dan bermutu. Sejalan dengan hal tersebut Indonesia termasuk ke dalam negara kepulauan di dunia dengan luas perairan lebih besar dari pada luas daratan, maka dari itu Indonesia juga disebut sebagai Negara Maritim [4].

Seiring dengan program kerja pemerintah saat ini dimana akan dibukanya tol laut, maka akan sangat banyak di butuhkan alat transportasi laut. Proses pembangunan kapal pada galangan demi meningkatakan efisiensi maka menggunakan proses system block dimana proses penyambungannya (joint erection) harus diperhatikan jaraknya agar terhindar dari cacat pada pengelasan [1] .

Kapal dengan proses pengerjaan dengan menggunakan sistem seksi atau block biasanya diberlakukan pada kapal dengan jenis material yang homogen atau sejenis [3] Dalam hal ini kapal yang digunakan dalam penelitan adalah kapal baja dengan panjang 55 meter termasuk jenis kapal cepat . Kapal patrol di desain memeiliki bentuk lambung yang ramping.

Tujuan dari penelitian ini adalah untuk mengetahui :

1) Peralatan untuk pengerjaan Fit Up Join Erection

2) Toleransi maksimal jarak antar block Saat dilakukan Fit Up Joint Erection 
3) Dampak kesalahan pengerjaan Fit $U p$ Joint Erection terhadap kualitas sambungan las antar block.

\section{Metode Penelitian}

\subsection{Sistem Block}

Sistem block adalah sistem pembuatan kapal dimana badan kapal terbagi beberapa block, dimana tiap-tiap block sudah siap pakai [5]. (lengkap dengan sistem perpipaan nya). Pembangunan dengan sistem blok ini biasanya diterapkan untuk kapal-kapal yang berukuran besar dimana konstruksi masingmasing blok dpat dibangun dalam waktu yang bersamaan dan dilakukan ditempat yang terpisah serta baru digabung setelah masingmasing block selesai dibangun. Dengan melihat proses pembangunan ini makan perkerjaan pengelasan dibengkel produksi relatif banyak. Sehingga pekerjaan lebih cepat dilakukan mengingat operator mesin las dapat menjalankan lebih dari satu mesin otomatis dengan posisi datar. Dengan peran lebih ini akan banyak menguranfi jumlah pekerja di bengkel atau dipelantaran pembangunan kapal dan akan mendapatkan kecepatan pengelasan lebih cepat.

Metode block merupakan perkembangan dari metode seksi yaitu dengan cara menggabungkan beberapa seksi di bengkel produksi perakitan menjadi satu block atau ring seksi yang besarnya block disesuaikan dengan kapasitas alat angkat dan angkut yang dimiliki oleh galangan, lihat pada gambar 1 . Pembangunan dengan metode block ini pada prinsipnya adalah :

1) Penggabungan block yang lengkap terdiri atas lambung, sekat dan geladak yang sebelumnya di kerjakan dibengkel produksi perakitan.

2) Pada saat dilandasan pembangunan dilakukan penyambungan block-block yang telah membentuk ring seksi menjadi bentuk badan kapal yang berupa grand assembly atau erection.
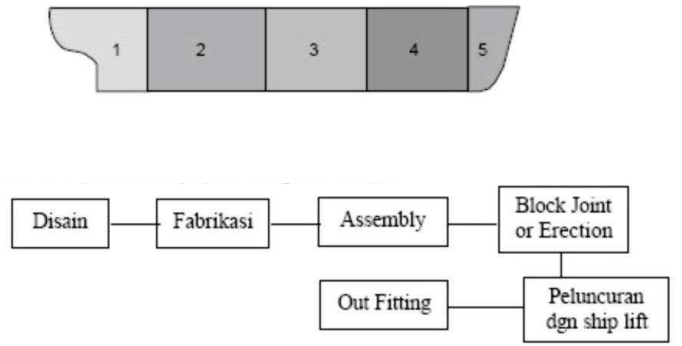

\section{Gambar 1. Alur pembangunan kapal} sistem block

Adapun keuntungan dari pembangunan kapal dengan sistem block dimana pembangunan kapal sistem blok ditinjau dari segi pengelasannya maka proses pembangunan kapal dengan sistem blok mempunyai beberapa keuntungan di banding dengan sistem seksi antara lain : waktu pembangunan lebih singkat, memudahkan pengelasan, pekerjaan didalam dok atau diatas pelataran penyambungan kapal lebih singkat sehingga fasilitas mesin las dapat di operasikan dengan efektif, kontrol terhadap proses pembentukan dan teknik pengelasan dapat lebih mudah, dapat mengurangi pekerjaan las ditempat yang tinggi atau tempat yang sempit sehingga lingkungan dan keselamatan juru las akan lebih terjamin[7].

Sedangkan kendala yang sering terjadi dan timbul dalam proses fairing yang dilakukan dengan blander pemanas tidak dilakukan dengan pengecekan suhu material saat dipanaskan. Material yang dipanaskan dibiarkan sampai memerah baru kemudian ditarik lagi. Saat memerah ini, kemungkinan besar material telah mencapai temperatur AC1 yaitu temperatur di mana struktur material tersebut telah mulai berubah dan biasanya berubah menjadi martensit (menjadi lebih brittle) [8]. Kondisi ini diperparah, karena pada saat itu, material ditekuk. Hasil dari proses fairing ini beresiko tinggi mengalami penurunan mechanical properties[10].

Sangat berbahaya bila material yang telah difairing ini digunakan untuk bagian konstruksi yang menerima beban langsung dan berat seperti kantilever dan lain-lain. 


\section{- Fitting Fabrication}

Adalah penyetelan material-material yang akan digabungkan, misalnya penyetelan antara pembujur dengan pelat, dll.

\section{- Welding Fabrication}

Penyambungan bagian-bagian yang telah dipasang dengan cara pengelasan. Sebelum itu pada material yang akan digabung dipasang stoper yang berfungsi untuk mencegah deformasi.

\subsection{Fit Up Joint Erection}

Pada pembangunan suatu kapal baru,tentu sangat banyak hal-hal yang harus di perhatikan dalam setiap tahap pengerjaan seperti: Persyaratan class,sertifikat material dan sejenisnya. Control quality baik di dalam maupun di luar lapangan sangatlah penting agar mendapatkan hasil yang maksimal dan memuaskan pelanggan. Banyak hal yang harus di periksa secara detail pada saat pengerjaan di lapangan. Kesigapan seorang Quality Control sangatlah di perlukan untuk mengetahui apa apa saja kesalahan-kesalahan yang terjadi dan seharusnya di perbaiki oleh para pekerja [6]. Adapun pengecheckan yang sering di lakukan antara lain: welding Check, Aligment Check, Scantling Check dan tentunya pada saat pengerjaan Fit Up Joint Erection. Semua chek chek tersebut pastinya berbeda fungsi dan Kegunaannya.

Oleh sebab itu Fit Up Joint Erection sangatlah penting dalam pembangunan kapal baru, dimana pengerjaan ini biasanya menimbulkan dampak yang sangat fatal baik terhadap kualitas pengelasan , mempengaruhi data ukuran utama kapal , dan sebagainya . Fit Up joint erection yang salah dapat menimbulkan kerugian yang begitu signifikan serta pemunduran jadwal pengerjaan sehingga harus di perhatikan dengan baik dan seksama.

Prinsip dari Fit Up Joint Erection sendiri adalah melakukan penyetelan 2 block menjadi satu parameter. Pada saat pengerjaan banyak hal-hal yang harus di perhatikan seperti: ukuran gap antar block yang di tentukan oleh class, Hi-Low, Aligment antara block yang satu dengan block lainnya,serta deformasi yang akan terjadi [5].

Fit Up Joint Erection sendiri lebih sering digunakan untuk bangunan baru yang building berth. Pada saat di Fit Up kita harus benar benar melakukan pengukuran tehadap:

1) Ukuran Gap yang telah di tentukan oleh class. Ukuran Gap antar Block harus di ukur setiap sisi yang akan di sambung, untuk menghindari perbedaan ukuran gap pada sisi yang satu dengan sisi lainnya

2) Ukuran Hi-Low pada plat yang akan di sambung Pada saat penyetelan,sering sekali terjadi deformasi pada plat,sehingga pengecekan $\mathrm{Hi}$-Low sangatlah perlu untuk meminimalisir terjadinya cacat lasan ketika akan dilakukan penyambungan

3) Aligment pada Setiap block

Hal ini sangat di perlukan untuk menyesuaikan komponen komponen kontruksi tersambung dengan baik sesuai dengan yang seharusnya. Seperti penyesusian Center Girder agar tetap lurus dan tidak melenceng

4. Deformasi

Pada saat dilakukan pengelasan antar blok yang satu dengan block yang lainnya pasti akan terjadi deformasi sehingga pengecheckan dilakukan setiap waktu untuk menanggulangi plat kulit menjadi berkerut dan dapat menyebabkan penolakan oleh class [10].

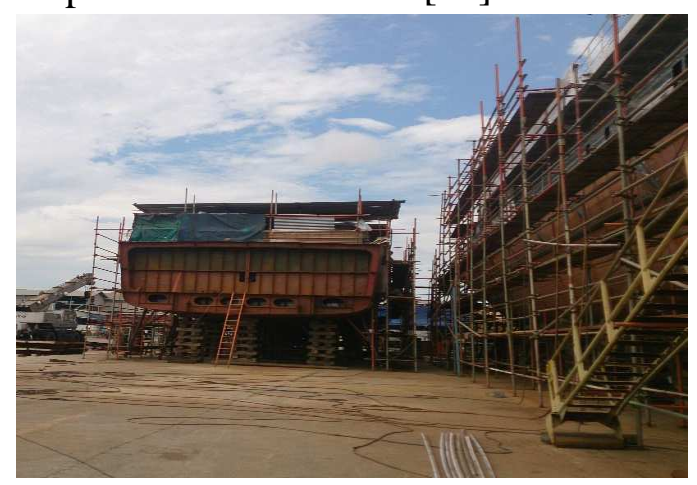

Gambar 2. Pembangunan kapal sistem block 


\section{Hasil Dan Pembahasan}

Data Kapal Patroli Polisi - Kelas A2 -55 meter :

$\begin{array}{ll}\text { Length Over All (LOA) } & : 55,00 \mathrm{M} \\ \text { Length Perpendicular (LPP) } & : 50,761 \mathrm{M} \\ \text { Breadth (B) } & : 8,2 \quad \mathrm{M} \\ \text { Height (T) } & : 4,55 \mathrm{M} \\ \text { Draft (d) } & : 2,00 \mathrm{M}\end{array}$

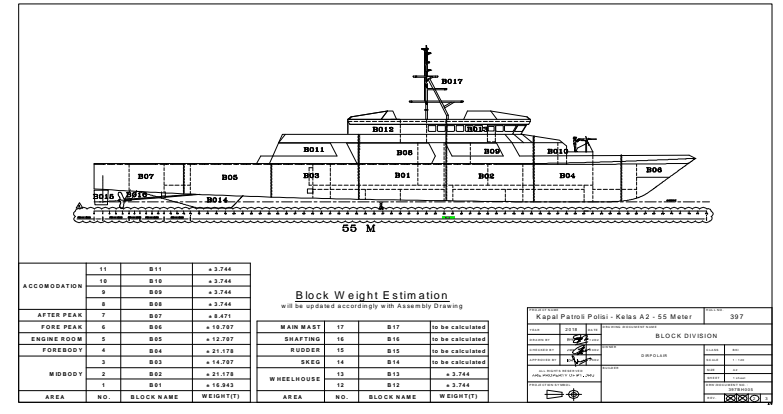

Gambar 3. Block Division Kapal

Proses Fit Up Joint Erection diawali pengangkatan block 07 yang akan di sambung menggunakan crane, pada saat blok di angkat dan di pindahkan ke atas dudukan stop blok maka Quality Contol untuk memastikan apakah Gap , Aligment, Hi-Low Bevel Sambungan, Deformasi sudah sudah memenuhi persyaratan yang di berikan oleh BKI,dan WPS [8].

Adapun ketentuan/prosedur pengerjaan Fit Up Joint Erection ini adalah sebagai berikut:

1) Jarak Gap yang digunakan

Untuk Gap yang di gunakan dalam Joint Erection adalah $3 \mathrm{~mm}$ sesuai dengan permintaan class BKI, lihat gambar 4 .

2).Ukuran dan bentuk Bevel yang di gunakan Biasanya untuk pengelasan Joint Erection menggunakan Bevel $\mathrm{V}$ dengan ukuran sudut menyesuaikan dengan keadaan lapangan [9].

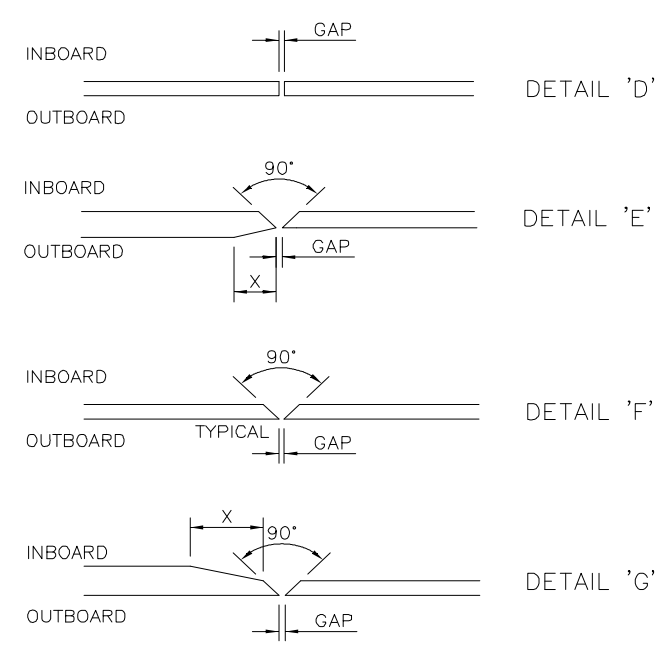

\section{Gambar 4. Gap untuk Joint Erection}

Dalam melaksanakan kegitan Fit Up Joint Erection ada beberapa toleransi yang di berikan sebelum atau sesudah pengerjaan dilakukan .

\section{Tabel 1. Tabel Toleransi Gap}

\begin{tabular}{|c|c|c|c|c|c|}
\hline PLATE & PREP & DETAIL & BEVEL ' $X$ ' & GAP & PASS \\
\hline $3-3$ & NONE-SQUARE EDGE & 'D' & NONE & $2-3 \mathrm{~mm}$ & 1 PASS \\
\hline $3-4$ & NONE-SQUARE EDGE & 'D' & NONE & $2-3 \mathrm{~mm}$ & 1 PASS \\
\hline $4-4$ & NONE-SQUARE EDGE & 'D' & NONE & $2-3 \mathrm{~mm}$ & 1 PASS \\
\hline $4-5$ & NONE-SQUARE EDGE & 'D' & NONE & $2-3 \mathrm{~mm}$ & 1 PASS \\
\hline $4-6$ & CHAMFER $45^{\circ}$ & 'F' & NONE & $1-3 \mathrm{~mm}$ & 1 ROOT 1 CAP \\
\hline $4-8$ & BEVEL \& CHAMFER $45^{\circ}$ & 'E' & 1:4 TAPER & $1-3 \mathrm{~mm}$ & 1 ROOT 1 CAP \\
\hline $4-10$ & BEVEL \& CHAMFER $45^{\circ}$ & ' 6 ' & 1:4 TAPER & $1-3 \mathrm{~mm}$ & 1 ROOT 1 CAP \\
\hline $5-5$ & NONE-SQUARE EDGE & 'D' & NONE & $2-3 \mathrm{~mm}$ & 1 PASS \\
\hline $5-6$ & NONE-SQUARE EDGE & 'D' & NONE & $2-3 \mathrm{~mm}$ & 1 PASS \\
\hline $5-7$ & CHAMFER $45^{\circ}$ & ' $F$ ' & NONE & $1-3 \mathrm{~mm}$ & 1 ROOT 1 CAP \\
\hline $5-10$ & BEVEL \& CHAMFER $45^{\circ}$ & ' $G$ ' & 1:4 TAPER & $1-3 \mathrm{~mm}$ & 1 ROOT 1 CAP \\
\hline $6-6$ & CHAMFER $45^{\circ}$ & 'F' & NONE & $1-3 \mathrm{~mm}$ & 1 ROOT 1 CAP \\
\hline $6-8$ & CHAMFER $45^{\circ}$ & ' $F$ ' & NONE & $1-3 \mathrm{~mm}$ & 1 ROOT 1 CAP \\
\hline $\begin{array}{l}8-8 \\
8-10\end{array}$ & $\begin{array}{l}\text { CHAMFER } 45^{\circ} \\
\text { BEVEL }\end{array}$ & 'F' & NONE & $1-3 \mathrm{~mm}$ & 1 ROOT 1 CAP \\
\hline
\end{tabular}

Pada tabel 1 tersebut, kita dapat mengetahui batsasan berapa jarak minimal yang diperlukan untuk proses penyambungan block pada pembangunan kapal baru. 


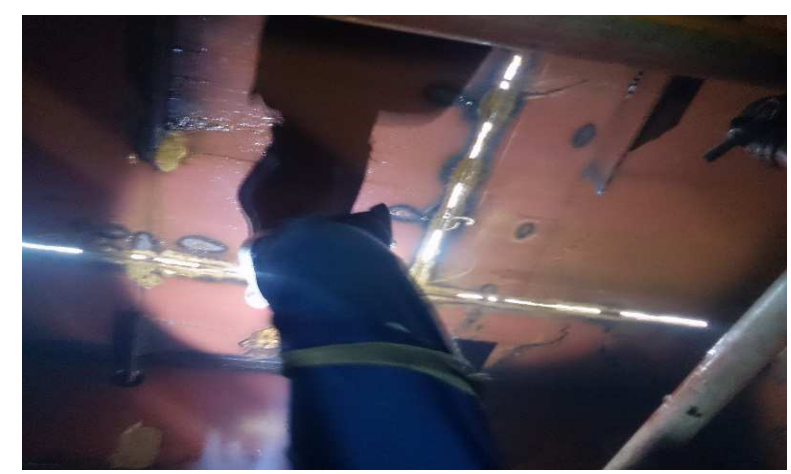

Gambar 5. Pengukuran gap sebelum joint Erection Block

Proses pengukuran ini menggunakan alat mistar atau menggunakan alat ukur lainnya seperti jangka sorong / filler, lihat pada gambar 5. Pengukuran tersebut dilakukan sebelum block dilaksanakan pengelasan. Setelah dilakukan penyetelan maka block saling dikunci dengan carling yang di tempatkan di lambung block kapal, pada gambar 6 .

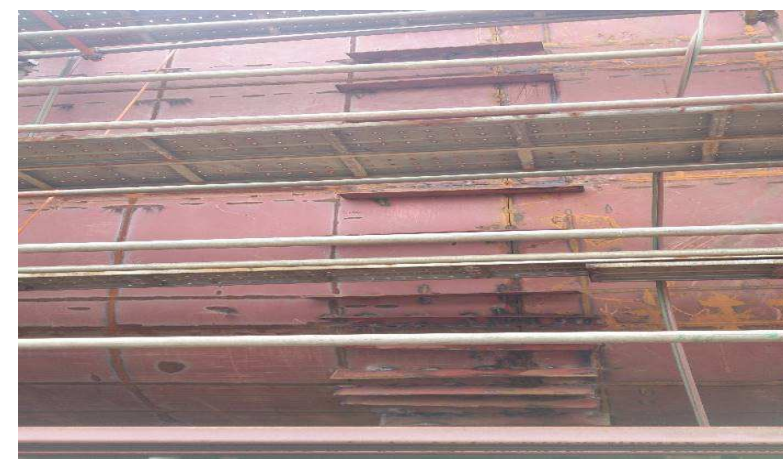

Gambar 6. Hasil penyetelan block setelah di ukur gap-nya.

\section{Kesimpulan}

Fit Up Joint Erection adalah suatu kegiatan penyetelan dua block ke dalam satu parameter. Kesalahan dalam penyetelan baik Gap,Hi-Low,Aligment krontuksi yang tidak sesuai,dan deformasi sangat berdampak terhadap gagal atau tidaknya suatu pengerjaan bahkan dapat mengakibatkan pemunduran jadwal proyek akibat tidak adanya penerimaan dari class yang bersangkutan dan mengakibatkan kerugian besar pada suatu perusahaan.

Adapun hal yang mempengaruhi kualitas hasil pengelasan pada pengerjaan sambungan joint erection diantaranya : perbandingan tinggi-rendahnya perbedaan pada konstruksi block kapal, Gap yang tidak sesuai dengan permintaan atau toleransi yang berlaku, Sudut Bevel tidak sesuai mengaibatkan sambungan pengelasan mengalami cacat dalam pengelasan ( incomplete penetration, crack in layer, crack root) sehingga dapat mengakibatkan kebocoran pada lambung kapal.

\section{Daftar Pustaka}

- Biro Klasifikasi Indonesia . 2018. Rules for The Clasification and Construction of Seagoing Stel Ships, Volume II, Rules For Hull, Edition 2018. BKI. Jakarta

- Djaya, I,K. 2008. Teknik Konstruksi Kapal Baja jilid 2.Jakarta : BSE

- Han, K. ed., 2006. A Study on Enhancing Precision for Mid and Small size Ship Block Assembly. Final Report of Regional Industry Promotion \& Development Research, Ministry of Commerce, Industry and Energy.

- Lee D.H., Kang Y.W., Kim H.J. 2005. Block Assignment planning for shipbuilding considering preference shop and load balancing. Daewoo Shipbuilding \& Marine Engineering Research report, 61 (2) (2005), pp. 32-41.

- Lee J.M. 2007 . An integrated process and measurement framework for planning production of large shipyards. $\mathrm{PhD}$ thesis, Seoul National University

- Lee K.K., Shin J.G., Ryu C. 2009. Development of simulation based production execution system in a shipyard: a case study for a panel block assembly shop. Production Planning \& Control, 20 (8) (2009), pp. 750-768.

- Sasono A,J, Sulaiman, Darmanto S, Proyono E. 2014. Analisa Perbandingan Laju Korosi lambung kapal dengan Aplikasi Paduan Alumunium. TEKNIS Volume 8 no 2 hal 28-34. 
- Shin J.G., Kwon O.H., Ryu C. 2008. Heuristic and metaheuristic spatial planning of assembly blocks with process schedules in an assembly shop using differential evolution. Production Planning \& Control, 19 (6) (2008), pp. 605-615.

- Shin J.G., Hwang, H,I . 2014. Automation of block assignment planning using a diagram-based scenario modeling method.International Journal of Naval Architecture and Ocean Engineering, 6 (1), pp 162-174.
- Sulaiman. Julianto Eko.2015. Perubahan Nilai Kekerasan Pelat Baja Kapal Dengan Perlakuan Bending Line Heating. TEKNIS Volume 10 no 2 hal 76-80. 